\title{
Cultura Abierta
}

Fernando Martínez Abad; Jorge Jiménez López; Begoña Lázaro Blanco; Laura Ranero Riestra; José Carlos Sánchez Prieto

\section{CULTURA ABIERTA}

$\mathrm{E}$

STE PROYECTO NACE con el interés de dar respuesta a la dificultad de acceso a la cultura por parte de colectivos en riesgo de exclusión, derecho fundamental escasamente atendido.

Para ello se promueve la difusión del patrimonio material e inmaterial desde la Universidad de Salamanca, sensibilizando a diferentes colectivos sobre su importancia gracias a la metodología de Aprendizaje y Servicio (ApS).

El alumnado participante pertenece a los Grados en Historia del Arte, Lenguas, Literaturas y Culturas Románicas, Educación Social y Pedagogía y se encargaron de la planificación y el desarrollo del conjunto de actividades.

Este proyecto tiene como objetivo general la adquisición por parte de los estudiantes de competencias prácticas académicas y laborales dirigidas a la difusión y educación en este ámbito.

El plan de trabajo se desarrolló en ocho fases:

1. Contacto inicial con los estudiantes interesados.

2. Reuniones de coordinación con los estudiantes para determinar responsabilidades y cronograma de trabajo.

3. Diseño de la propuesta de actividades adaptada a los colectivos diana.

4. Contacto con las Entidades interesadas y concreción de las actividades a desarrollar.

5. Formación genérica de los estudiantes en el SAS de la USAL en pautas de atencióna colectivos en riesgo.

6. Formación específica en cada Entidad en función de las necesidades específicas.

7. Desarrollo de las actividades en cada Entidad.

8. Evaluación del proyecto mediante cuestionarios de satisfacción. 
En cada una de las fases anteriores, los alumnos contaron con el apoyo de los coordinadores del proyecto, profesores expertos en distintas especialidades respectivamente.

Tras la selección de los participantes, se procedió a definir los ámbitos de actuación, que fueron: expresión artística, intercambio cultural, formación y recursos culturales y ocio y tiempo libre.

Tras el envío del catálogo a las instituciones, los coordinadores se reunieron con los colectivos interesados para determinar las actividades a desarrollar en cada institución.

Se persigue la transferencia, innovación y creatividad, impulsando el emprendimiento social y vinculando el aprendizaje con las salidas profesionales de las distintas titulaciones.

Los estudiantes se organizan en grupos de trabajo según las áreas de interés, siendo responsable cada grupo de trabajo del diseño, planificación y desarrollo de los talleres.

Se implicaron un total de 34 estudiantes de los Grados anteriormente mencionados.

Los colectivos destinatarios fueron: personas mayores, personas con discapacidad, personas migrantes y refugiadas, zonas rurales y colectivo gitano.

Se desarrollaron un total de 25 talleres y actividades.

Con la aplicación de la metodología ApS se ha facilitado el desarrollo en los estudiantes de diferentes competencias y se ha contribuido al bienestar social y la transmisión cultural.

Para su divulgación social se estableció el grupo de Facebook «Cultura Abierta», en el que se fueron publicando todas las actividades desarrolladas en el marco del proyecto. El grupo ha publicado y compartido más de 70 posts y cuenta con casi 100 seguidores. 